\title{
Passive self-tuning inductor for piezoelectric shunt damping considering temperature variations
}

\author{
R. Darleux*, B. Lossouarn, J.-F. Deü \\ Laboratoire de Mécanique des Structures et des Systèmes Couplés (LMSSC) \\ Conservatoire national des arts et métiers (Cnam) \\ 292 rue Saint-Martin, 75003 Paris, France
}

\begin{abstract}
Piezoelectric shunt damping offers a passive solution to mitigate mechanical vibrations: the electromechanical coupling induced by piezoelectric patches bound to the vibrating structure allows the transfer of vibration energy to an electrical circuit, where it can be dissipated in a resistive component. Among the existing passive piezoelectric shunt circuits, the resonant shunt leads to significant vibration damping if it is tuned with enough precision. However, temperature may have a strong influence on electrical parameters such as the piezoelectric capacitance and the circuit inductance. As a consequence, a temperature variation can lead to a deterioration of vibration damping performance. This paper describes how inductive components can be chosen to minimize the mistuning of the resonant shunt when temperature evolves. More specifically, inductors are made of magnetic cores whose magnetic permeability varies with temperature, which counterbalances the variations with temperature of the mechanical resonance frequency and of the piezoelectric capacitance. Experiments show the benefits of adequately choosing the magnetic material of the inductor for vibration damping of a cantilever beam. The concept of a fully passive shunt adapting to temperature variations is hence validated.
\end{abstract}

Keywords: Passive vibration damping, Resonant piezoelectric shunt, Temperature influence, Magnetic cores

\section{Introduction}

The direct and inverse piezoelectric effects allow piezoelectric materials to create an electromechanical coupling between mechanical and electrical domains. Since the nineties, vibration damping by bonding piezoelectric patches to lightweight mechanical structures has been studied. The electromechanical coupling enables transferring part of the mechanical energy to an electrical circuit, where it can be dissipated in a resistive component. The use of piezoelectric shunts, first proposed by Forward [1, stands as a relatively simple vibration damping solution. In 1991, Hagood and von Flotow 2] developed the concept of the resonant shunt, which is the electrical analogue of a tuned mass damper [3, also called dynamic vibration absorber. Since then, different types of resonant shunts have been developped to damp a single mechanical resonance [4-7, as well as several resonances thanks to multi-branch shunts 8 11] or interconnected arrays of piezoelectric patches 12 14.

The resonant shunt provides a significant vibration damping around the electrical resonance angular frequency $\Omega_{\mathrm{e}}=2 \pi f_{\mathrm{e}}=1 / \sqrt{L C}$, where $f_{\mathrm{e}}$ is the electrical resonance frequency, $L$ is the inductance and $C$ is the capacitance of the piezoelectric patches. The literature is abundant on techniques to properly tune resonant shunts [6, 15] 19]. A commonly accepted result is that the electrical resonance frequency should be

\footnotetext{
* Corresponding author

Email address: robin.darleux@lecnam.net (R. Darleux)
} 
set sufficiently close to the mechanical resonance frequency. The main drawback of this technique is the need of a precise tuning of the electrical parameters to ensure the performance of the resonant shunt [6, 17, 20, 21]. Temperature is one of the environmental parameters that have a significant impact on the resonant shunt tuning. Indeed, piezoelectric materials properties vary with temperature [22 24], especially the piezoelectric capacitance. Then, Park and Han 25 have shown that the degradation of resonant shunts performance when temperature evolves is mainly caused by variations of both the piezoelectric patches parameters and the inductance. Niederberger [26] has thus developed an autonomous switching shunt which can adapt to temperature variations, but the overall damping performance is limited to around $6 \mathrm{~dB}$ vibration reduction with the proposed setup. Other adaptive piezoelectric shunts have been proposed [27, 28, but they are not autonomous passive solutions since they require external power supply.

The contribution of this paper is the validation of a fully passive resonant shunt that would remain correctly tuned in case of temperature variations. The resonant shunt is kept tuned by using a variable inductor that makes the electrical resonance frequency of the system evolve in the same manner as the mechanical resonance frequency. This principle has been recently proposed in [29], where a nonlinear mechanical system is damped with a fully passive but adaptive piezoelectric resonant shunt subjected to variations of the electrical current. The former principle is here extended to a case where temperature is the main parameter inducing variation of the equivalent inductance value.

The following section presents an electromechanical model to estimate the influence of temperature on damping performance of resonant shunts. A tuning condition of the resonant shunt is expressed. Then, the experimental setup is described in section 3 In the same section, the evolution with temperature of the mechanical resonance frequency and the piezoelectric capacitance are measured from room temperature to around $60^{\circ} \mathrm{C}$. As a consequence, inductive components, made by winding turns of conductive wire around magnetic cores, are designed by taking into account the temperature characteristics of the cores magnetic permeability. The influence of the air gap on the inductance value is highlighted, and the resulting inductive components are then characterized when subjected to temperature and electrical current variations. Finally, in section 4, practical validation in forced vibration at different temperatures is performed. Experiments highlight that it is possible to counterbalance the variations with temperature of the mechanical resonance frequency and of the piezoelectric capacitance with inductance variations, and so to mitigate the influence of temperature on damping performance. When the magnetic material of the inductor is adequately chosen to satisfy the tuning condition, the damping performance of the resonant shunt is maintained from room temperature to around $50^{\circ} \mathrm{C}$.

\section{Electromechanical model for piezoelectric shunts}

An electromechanical model of the shunted vibrating structure is derived from the governing equations of piezoelectricity. The case of the resonant shunt is studied, and the importance of its tuning is highlighted. The influence of temperature on the tuning condition is then expressed from linear variations of the involved quantities.

\subsection{Governing equations}

The piezoelectric effect allows some materials under stress to produce a potential difference between their electrodes. Conversely, these materials get under stress when subjected to an electrical field. These are called the direct and inverse piezoelectric effects, respectively. The 3D governing equations of the piezoelectric materials behavior is given in [30] by

$$
\begin{aligned}
\varepsilon_{i j} & =s_{i j k l}^{E} \sigma_{k l}+d_{k i j} E_{k}, \\
D_{i} & =d_{i k l} \sigma_{k l}+\epsilon_{i k}^{\sigma} E_{k},
\end{aligned}
$$

where $\varepsilon_{i j}, \sigma_{k l}, E_{k}$ and $D_{i}$ are the strain, stress, electrical field and electrical displacement variables, respectively. The $s_{i j k l}^{E}, \epsilon_{i k}^{\sigma}$ and $d_{i k l}$ constants are the elastic compliance under constant electrical field, the electric permittivity under constant stress, and the piezoelectric constants which represent the electromechanical 


\begin{tabular}{|ccc|}
$\frac{\text { Mechanical quantity }}{\text { Force }}$ & & $\frac{\text { Electrical quantity }}{\text { Voltage }}$ \\
Velocity & $\longleftrightarrow$ & Electrical current \\
Compliance & $\longleftrightarrow$ & Capacitance \\
Mass & $\longleftrightarrow$ & Inductance \\
Viscous damping & $\longleftrightarrow$ & Resistance \\
\hline
\end{tabular}

Table 1: Direct electromechanical analogy.

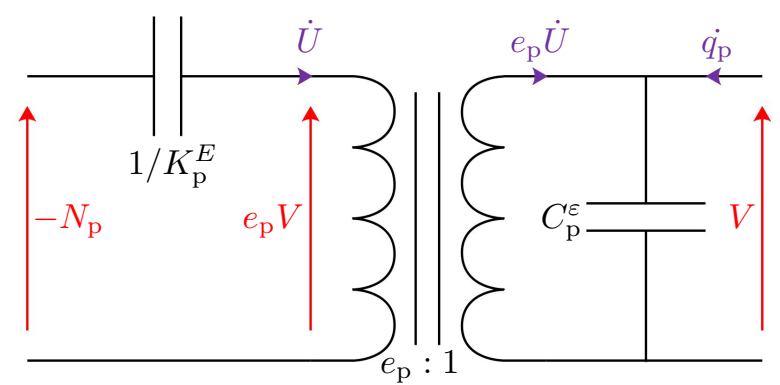

Figure 1: Equivalent electrical model of a piezoelectric transducer.

coupling, respectively. Under the assumption of a transverse isotropic piezoelectric material being polarized in the ' 3 ' direction and free in the other directions, Eq. (1) is simplified as

$$
\begin{aligned}
& \varepsilon_{11}=s_{11}^{E} \sigma_{11}+d_{31} E_{3}, \\
& D_{3}=d_{31} \sigma_{11}+\epsilon_{33}^{\sigma} E_{3} .
\end{aligned}
$$

A thin patch of length $l_{\mathrm{p}}$, width $b_{\mathrm{p}}$ and thickness $h_{\mathrm{p}}$ is considered. The electrical field is supposed constant along the polarization direction, thus $E_{3}=-V / h_{\mathrm{p}}$, where $V$ is the voltage between the two electrodes of the patch. In the case of a one-dimensional mechanical model, if the considered wavelength is large enough compared to $l_{\mathrm{p}}$, the strain can be assumed uniform along the patch and expressed with the displacement $U$ in the longitudinal direction by the relation $\varepsilon_{11}=U / l_{\mathrm{p}}$. We define $q_{\mathrm{p}}$ as the electric charge on an electrode, and $N_{\mathrm{p}}$ as the normal force applied to the patch. The electric charge $q_{\mathrm{p}}$ is linked to the electrical displacement by $q_{\mathrm{p}}=-l_{\mathrm{p}} b_{\mathrm{p}} D_{3}$. The longitudinal stress $\sigma_{11}$ is supposed uniform along the cross-section $h_{\mathrm{p}} b_{\mathrm{p}}$, so the normal force is $N_{\mathrm{p}}=\sigma_{11} h_{\mathrm{p}} b_{\mathrm{p}}$. Hence, Eq. (1) can be transformed in

$$
\begin{aligned}
N_{\mathrm{p}} & =K_{\mathrm{p}}^{E} U-e_{\mathrm{p}} V, \\
q_{\mathrm{p}} & =C_{\mathrm{p}}^{\varepsilon} V+e_{\mathrm{p}} U,
\end{aligned}
$$

with $K_{\mathrm{p}}^{E}$ the patch stiffness at constant electrical field, $e_{\mathrm{p}}$ the longitudinal coupling coefficient, and $C_{\mathrm{p}}^{\varepsilon}$ the piezoelectric capacitance at constant strain, defined by:

$$
K_{\mathrm{p}}^{E}=\frac{h_{\mathrm{p}} b_{\mathrm{p}}}{l_{\mathrm{p}} s_{11}^{E}}, \quad e_{\mathrm{p}}=-\frac{b_{\mathrm{p}} d_{31}}{s_{11}^{E}}, \quad C_{\mathrm{p}}^{\varepsilon}=\left(\epsilon_{33}^{\sigma}-\frac{d_{31}^{2}}{s_{11}^{E}}\right) \frac{l_{\mathrm{p}} b_{\mathrm{p}}}{h_{\mathrm{p}}} .
$$

The equivalent electrical circuit of the system in Eq. (3) can be derived from an electromechanical analogy (see Table 11. This analogy is called direct electromechanical analogy [31, 32, and leads to the equivalent electrical circuit in Fig. 1. The coupling coefficient $e_{\mathrm{p}}$ highlights the electromechanical coupling and is analog to a transformer ratio. If $e_{\mathrm{p}}=0$, then the mechanical and electrical parts of the system are uncoupled and no energy transfer happens.

In the case of a piezoelectric patch covering a vibrating structure, it is assumed that the normal force $N$ and the electric charge $q$ are still linear combinations of $U$ and $V$. The corresponding global constants are $e$, 
which is the coupling coefficient, $K^{E}$, which represents the stiffness of the structure when the piezoelectric transducer is short-circuited (i.e. when $V=0$ ), and $C^{\varepsilon}$, which represents the piezoelectric capacitance when no structural displacement occurs (i.e. when $U=0$ ). These global constants take into account the whole system, and not only the mechanical properties of the piezoelectric transducer. The one-dimensional model of the piezoelectric patch bound to a vibrating structure is then:

$$
\begin{gathered}
N=K^{E} U-e V, \\
q=C^{\varepsilon} V+e U .
\end{gathered}
$$

To study the vibration damping around a single resonance, the mechanical vibrating system to which the piezoelectric patch is bound is modeled as an undamped one degree-of-freedom system. The structural damping is not taken into account, since it has little influence on the shunt performance in the case of a a slightly damped structure and a large enough coupling factor [6. If $m$ is the mass and $F$ the excitation force, the system dynamics is expressed by

$$
m \ddot{U}=F-N
$$

Combining Eq. (5) and Eq. (6) gives

$$
m \ddot{U}+K^{D} U=F+\frac{e}{C^{\varepsilon}} q
$$

with $K^{D}=K^{E}+e^{2} / C^{\varepsilon}$ the stiffness in open-circuit (i.e. when $q=0$ ). Eq. (7) highlights on its left side the equivalent mechanical parameters of the structure, and on its right side the external forces applied to it. The mechanical representation of this model is given in Fig. 2, We then define the mechanical resonance angular frequency in open-circuit $\Omega_{\mathrm{O}}$, the mechanical resonance angular frequency in short-circuit $\Omega_{\mathrm{S}}$ and the coupling factor $k_{\mathrm{c}}$ :

$$
\Omega_{\mathrm{O}}=\sqrt{\frac{K^{D}}{m}}, \quad \Omega_{\mathrm{S}}=\sqrt{\frac{K^{E}}{m}}, \quad k_{\mathrm{c}}=\sqrt{\frac{\Omega_{\mathrm{O}}^{2}-\Omega_{\mathrm{S}}^{2}}{\Omega_{\mathrm{S}}^{2}}} .
$$

In the case of a sinusoidal excitation at angular frequency $\Omega$, Eq. (7) becomes

$$
\left[1-\left(\frac{\Omega}{\Omega_{\mathrm{O}}}\right)^{2}\right] U=\frac{1}{K^{D}} F+\frac{k_{\mathrm{c}}^{2}}{e\left(1+k_{\mathrm{c}}^{2}\right)} q .
$$

If the piezoelectric patch is now connected to a $Z$ impedance, Ohm's law is

$$
V=-Z \dot{q}
$$

so using Eq. (5) the transfer function between the displacement $U$ and the electric charge $q$ is calculated:

$$
\frac{q}{U}=\frac{e}{1+\mathrm{j} \Omega C^{\varepsilon} Z}
$$

where $\mathrm{j}^{2}=-1$. In the end, combining Eq. (9) and Eq. (11) allows to define the dimensionless transfer function between the displacement and the excitation:

$$
\frac{U}{F / K^{D}}=\frac{1+\mathrm{j} \Omega C^{\varepsilon} Z}{\left[1-\left(\frac{\Omega}{\Omega_{\mathrm{O}}}\right)^{2}\right]\left(1+\mathrm{j} \Omega C^{\varepsilon} Z\right)-\frac{k_{\mathrm{c}}^{2}}{1+k_{\mathrm{c}}^{2}}} .
$$

The equivalent electrical model of the shunted structure is obtained by using the analogy presented in Table 1. The equivalent circuits of the piezoelectric transducer, the mechanical structure and the shunt impedance, are derived from Eq. (5), Eq. (6) and Eq. (10), respectively. The equivalent electrical circuit of the electromechanical system is represented in Fig. 3 . 


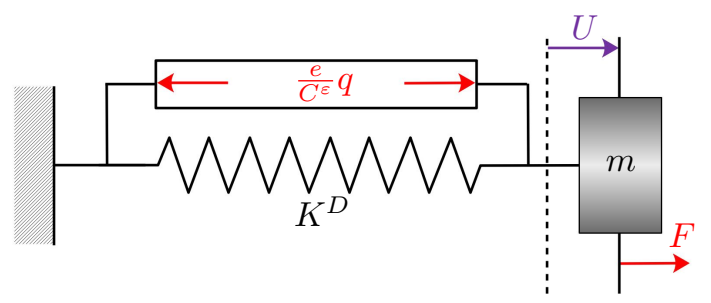

Figure 2: Equivalent mechanical model of the shunted structure.

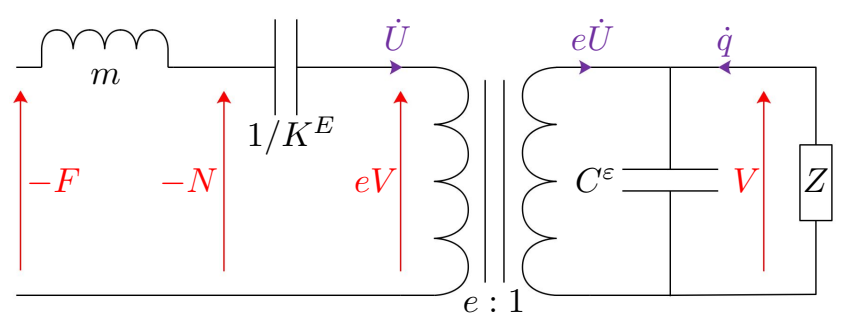

Figure 3: Equivalent electrical circuit of the shunted structure.

\subsection{Resonant shunt damping}

In the case of resonant shunt damping, the impedance is $Z=R+\mathrm{j} \Omega L$ with $R$ a resistance and $L$ an inductance. The transfer function in Eq. (12) then becomes

$$
\frac{U}{F / K^{D}}=\frac{1+2 \mathrm{j} \frac{\xi_{\mathrm{e}}}{\Omega_{\mathrm{e}}} \Omega-\left(\frac{\Omega}{\Omega_{\mathrm{e}}}\right)^{2}}{\left[1-\left(\frac{\Omega}{\Omega_{\mathrm{O}}}\right)^{2}\right]\left[1+2 \mathrm{j} \frac{\xi_{\mathrm{e}}}{\Omega_{\mathrm{e}}} \Omega-\left(\frac{\Omega}{\Omega_{\mathrm{e}}}\right)^{2}\right]-\frac{k_{\mathrm{c}}^{2}}{1+k_{\mathrm{c}}^{2}}},
$$

with $\Omega_{\mathrm{e}}$ the electrical resonance angular frequency and $\xi_{\mathrm{e}}$ the electrical damping defined by

$$
\Omega_{\mathrm{e}}=\frac{1}{\sqrt{L C^{\varepsilon}}}, \quad \xi_{\mathrm{e}}=\frac{R}{2} \sqrt{\frac{C^{\varepsilon}}{L}} .
$$

As previously stated, the literature is abundant on the study of resonant shunts and methods to tune the electrical resonance frequency and electrical damping. Considering the transfer function criterion presented in [6], the optimal values of these parameters are defined as follows:

$$
\left(\Omega_{\mathrm{e}}\right)_{\mathrm{opt}}=\Omega_{\mathrm{O}}, \quad\left(\xi_{\mathrm{e}}\right)_{\mathrm{opt}}=\sqrt{\frac{3}{8}} k_{\mathrm{c}} .
$$

The frequency response function (FRF) in Eq. (13) is plotted in Fig. 4. Variations of the electrical damping $\xi_{\mathrm{e}}$ are not shown, as its influence is small compared to $\Omega_{\mathrm{e}}$ variations [6, 17, 21, 25. The plotted FRFs highlight that the resonant shunt needs to be finely tuned to offer a significant vibration reduction around the mechanical resonance, as a detuning of $10 \%$ between $\Omega_{\mathrm{e}}$ and $\Omega_{\mathrm{O}}$ can add up to $12 \mathrm{~dB}$ to the transfer function peak. The damping performance would then be significantly reduced.

\subsection{Influence of temperature}

In order to maintain the resonant shunt performance, the electrical resonance frequency should stay equal to its optimal value in any situation. The evolution with temperature of the mechanical system is given data, since we suppose the structure is designed before any vibration damping considerations. Furthermore, the evolution with temperature of the piezoelectric capacitance is supposed known as it directly depends on 


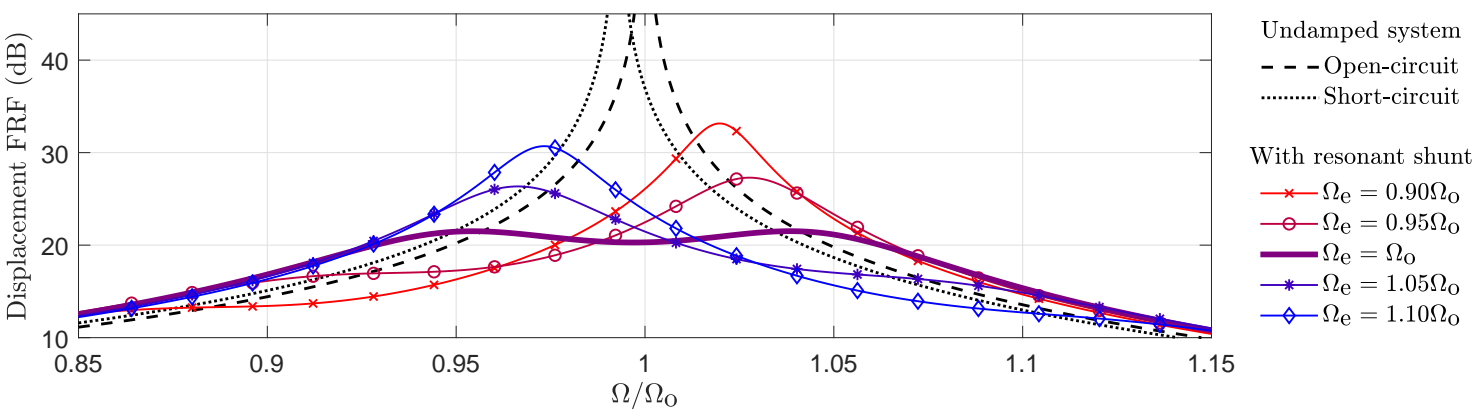

Figure 4: Displacement FRF around the resonance for $k_{\mathrm{c}}=0.12$ and $\xi_{\mathrm{e}}=\left(\xi_{\mathrm{e}}\right)_{\mathrm{opt}}$.

the permittivity $\epsilon_{33}^{\sigma}$ of the considered material, so it cannot be modified once the piezoelectric transducers are selected and bound to the structure. That makes the inductance the quantity to be controlled to keep the resonant shunt tuned. If temperature $T$ is not constant, the tuning condition on the inductance of the resonant shunt becomes

$$
L(T)=\frac{1}{\Omega_{\mathrm{O}}^{2}(T) C^{\varepsilon}(T)} .
$$

We assume that the mechanical resonance angular frequency $\Omega_{\mathrm{O}}$ and the piezoelectric capacitance $C^{\varepsilon}$ evolve linearly with temperature from room temperature $T_{0}$, which is $22^{\circ} \mathrm{C}$ in our case, to $60^{\circ} \mathrm{C}$. The associated temperature coefficients are noted $\alpha_{\Omega_{\mathrm{O}}}$ and $\alpha_{C^{\varepsilon}}$, respectively. Hence

$$
\begin{aligned}
\Omega_{\mathrm{O}}(T) & =\Omega_{\mathrm{O}}\left(T_{0}\right)\left[1+\alpha_{\Omega_{\mathrm{O}}}\left(T-T_{0}\right)\right], \\
C^{\varepsilon}(T) & =C^{\varepsilon}\left(T_{0}\right)\left[1+\alpha_{C^{\varepsilon}}\left(T-T_{0}\right)\right] .
\end{aligned}
$$

The tuning condition now becomes

$$
L(T)=\frac{L\left(T_{0}\right)}{\left[1+\alpha_{\Omega_{\mathrm{O}}}\left(T-T_{0}\right)\right]^{2}\left[1+\alpha_{C^{\varepsilon}}\left(T-T_{0}\right)\right]},
$$

with $L\left(T_{0}\right)=1 /\left(\Omega_{\mathrm{O}}^{2}\left(T_{0}\right) C^{\varepsilon}\left(T_{0}\right)\right)$. Assuming quantities $\alpha\left(T-T_{0}\right)$ are small compared to 1 in the $20^{\circ} \mathrm{C}$ $60{ }^{\circ} \mathrm{C}$ range (i.e. $\alpha_{C^{\varepsilon}}$ and $\alpha_{\Omega_{\mathrm{O}}} \ll 25 \cdot 10^{-3} \mathrm{~K}^{-1}$ ), a linear approximation of Eq. 18 shows that the evolution with temperature of the inductance should be

$$
L(T)=L\left(T_{0}\right)\left[1+\alpha_{L}\left(T-T_{0}\right)\right],
$$

with the temperature coefficient $\alpha_{L}$ defined by:

$$
\alpha_{L}=-\left(2 \alpha_{\Omega_{\mathrm{O}}}+\alpha_{C^{\varepsilon}}\right) .
$$

In the case of active and adaptive resonant shunts, these parameters variations can be taken into account and the electrical resonance frequency can be adjusted via the equivalent inductance value. However, in the case of fully passive damping, the shunt mistuning could become important. The goal is then to design a passive inductive component which satisfies Eq. 20), allowing the resonant shunt to stay tuned over a predefined range of temperature.

\section{Effects of temperature variations}

Vibration damping of a cantilever beam is now considered. The evolutions with temperature of the mechanical resonance frequency and the piezoelectric capacitance of patches bound to the beam are measured. The design of the inductive components is discussed, and two different magnetic materials are chosen for further investigations. Their characteristics are then compared to datasheets provided by magnetic core manufacturers. 


\begin{tabular}{|c|c|c|c|}
\hline Part & $\begin{array}{c}\text { Length } \\
(\mathrm{mm})\end{array}$ & $\begin{array}{c}\text { Width } \\
(\mathrm{mm})\end{array}$ & $\begin{array}{c}\text { Thickness } \\
(\mathrm{mm})\end{array}$ \\
\hline AU4G Beam & 170 & 25 & 2 \\
\hline PZT Patches & 25 & 20 & 0.5 \\
\hline
\end{tabular}

Table 2: Beam and piezoelectric patches dimensions.

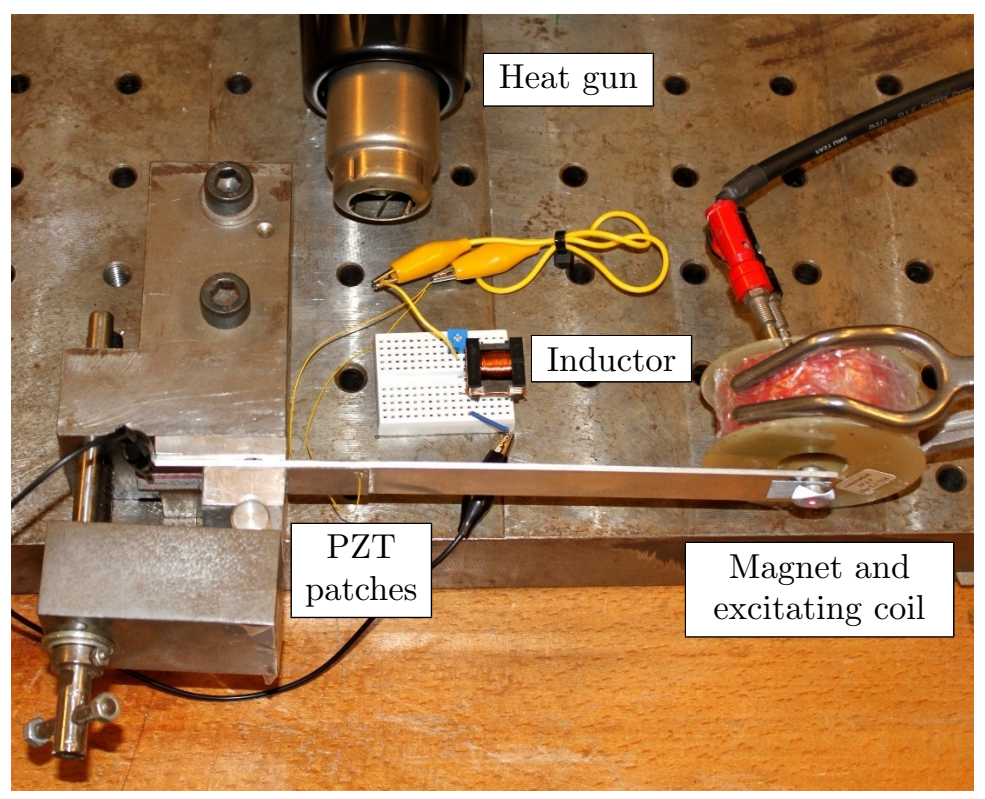

Figure 5: Experimental setup without the thermal chamber.

\subsection{Experimental setup}

In the experiments, bending vibrations are produced by placing at the free end of an aluminium beam a magnet subjected to an alternating magnetic field, which is generated by a nearby solenoid. The excitation system has been described in [6]. The displacement is then measured at the free end with a laser vibrometer. Two shunted piezoelectric patches have been fixed with the same poling directions at the beam clamped end. The aluminium beam is connected to one electrode of each piezoelectric transducer on one hand, and to the electrical ground on the other hand. The setup is shown in Fig. 5 . Dimensions of the beam and patches are given in Table 2. As represented in Fig. 6, the electromechanical system is then placed in a thermal chamber, which is heated by a heat gun. The thermal chamber is actually a nearly fully closed cardboard box. All measurements are performed in steady thermal state with an infrared thermometer.

For practical reasons related to inductive components production and magnetic materials availability, the second bending mode at $322 \mathrm{~Hz}$ has been selected for this study. The evolution with temperature of the mechanical resonance angular frequency $\Omega_{\mathrm{O}}$ in open-circuit is represented in Fig. 7. The identified temperature coefficient is $\alpha_{\Omega_{\mathrm{O}}}=-0.5 \cdot 10^{-3} \mathrm{~K}^{-1}$. For the sake of comparison, it can be noted that this temperature coefficient is in good agreement with the work of Park and Han [25. For example, the temperature coefficients from $20^{\circ} \mathrm{C}$ to $80^{\circ} \mathrm{C}$ of the Young's moduli of the aluminium beam and the piezoelectric material are $-0.6 \cdot 10^{-3} \mathrm{~K}^{-1}$ and $0.06 \cdot 10^{-3} \mathrm{~K}^{-1}$, respectively. These temperature coefficients would lead to a same order of magnitude for $\alpha_{\Omega_{\mathrm{O}}}$ as the one we measured. 


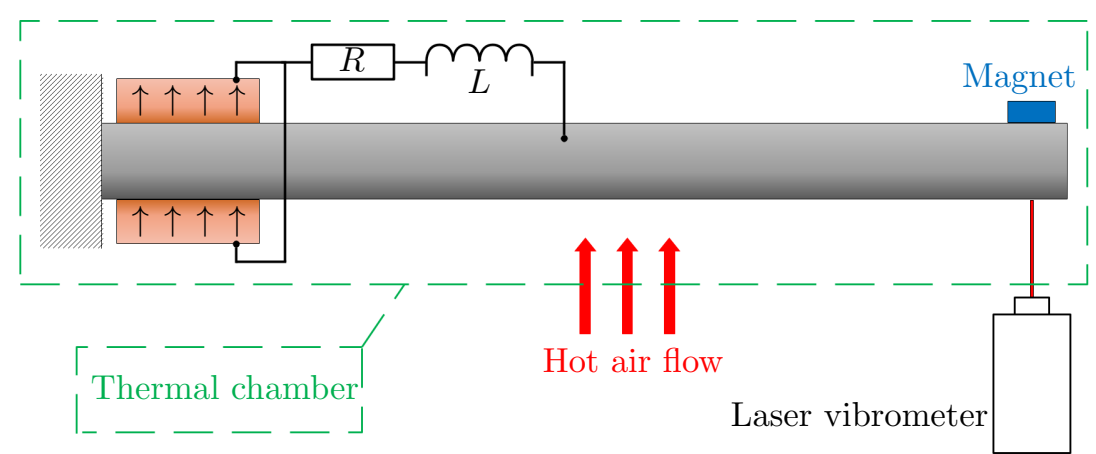

Figure 6: Sketch of the experimental setup inside the thermal chamber.

- Measurements - - - Linear regression

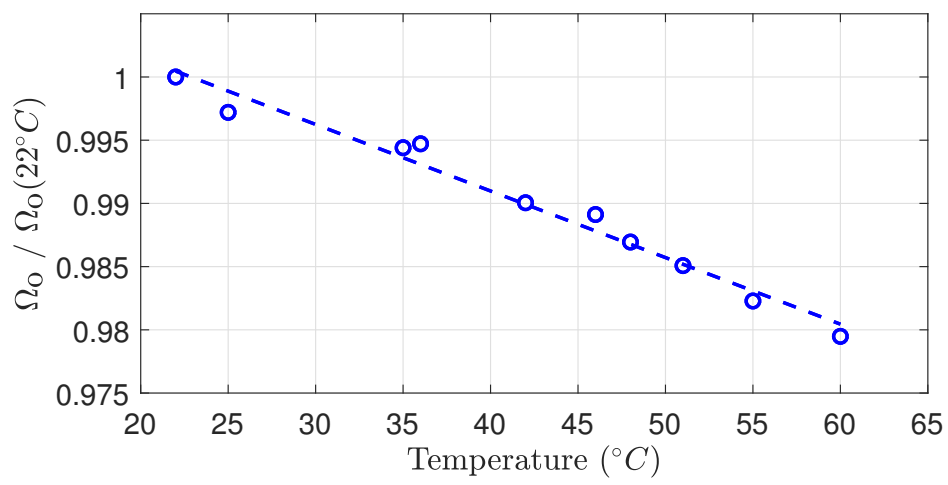

Figure 7: Evolution with temperature of the mechanical resonance angular frequency in open-circuit divided by its value at room temperature.

○ Measurements - - - Linear regression —-Datasheet

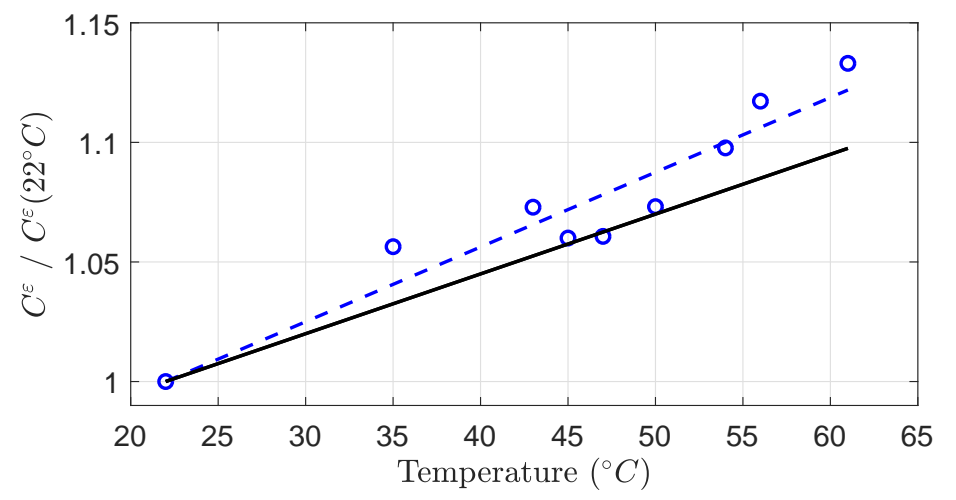

Figure 8: Evolution with temperature of the piezoelectric patches capacitance divided by its value at room temperature. 


\subsection{Piezoelectric capacitance}

The piezoelectric capacitance evolves with temperature. As to avoid detuning of the resonant shunt, the PIC 151 PZT material has been selected since its characteristics evolve with temperature at slowest rates among the available PI materials [33. Once glued onto the beam, the two patches are connected in parallel and their capacitance is measured at various temperatures with an LCR-meter. As explained by de Marneffe and Preumont in [34, 35, the impedance of the structure can be observed through a dynamic capacitance whose poles and zeros correspond to the mechanical resonances in short-circuit and open-circuit, respectively. The capacitance $C^{\varepsilon}$ for the second bending mode has to be measured between the second bending mode at $322 \mathrm{~Hz}$ and the third bending mode at $889 \mathrm{~Hz}$. The choice is made to define the capacitance at the mean value of these frequencies. Hence, its measured value at room temperature is $38.3 \mathrm{nF}$.

As illustrated in Fig. 8 , the capacitance increases by $12 \%$ from $22^{\circ} \mathrm{C}$ to $60{ }^{\circ} \mathrm{C}$. It is in agreement with available datasheets from the material manufacturer, though a remaining difference is visible in Fig. 8 . This difference can be attributed to three main causes. Firstly, experimental parameters, such as the excitation frequency, are not reported in datasheets and so could differ from the ones used in the present experiments. Secondly, a temperature increase might soften the adhesive layer between the beam and the patch, affecting the equivalent value of the piezoelectric capacitance. Finally, variations of the beam mechanical parameters have an effect on the piezoelectric capacitance because of the electromechanical coupling, and for this reason affect its measurement as well.

For this work, the considered linear regression coefficient is $\alpha_{C^{\varepsilon}}=3.1 \cdot 10^{-3} \mathrm{~K}^{-1}$. In [25], Park and Han used a temperature coefficient of $5.44 \cdot 10^{-3} \mathrm{~K}^{-1}$ from $20^{\circ} \mathrm{C}$ to $80{ }^{\circ} \mathrm{C}$, which is the order of magnitude of other PZT materials characteristics [33].

\subsection{Design of passive inductors}

Passive inductors are made by winding $N$ turns of conductive wire around magnetic cores of relative permeability $\mu_{e}$. Making inductors this way allows for high inductance and low resistance values, which fits the usual requirements of optimal electrical parameters of resonant shunts. The design of such inductors for piezoelectric shunt damping was first detailed in [36. The geometry of cores is characterized by the effective cross-sectional area $A_{e}$ and by the effective magnetic path length $l_{e}$. Denoting the vacuum permeability as $\mu_{0}$, the inductance is given by

$$
L=\mu_{e} \mu_{0} \frac{A_{e}}{l_{e}} N^{2}
$$

To keep the resonant shunt tuned when temperature rises, it has been shown in Eq. 20 that the inductance $L$ has to evolve in opposition to the mechanical resonance frequency and the capacitance variations. The main evolution with temperature in Eq. 21) is due to the relative permeability $\mu_{e}$, so the temperature coefficient $\alpha_{\mu_{e}}$ of the relative permeability should be equal to $\alpha_{L}$. Several ferrite materials from the same manufacturer have been compared and their temperature characteristics from datasheets are plotted in Fig. 9. This graph can be used to estimate $\alpha_{\mu_{e}}$ of the final inductive component. Concerning the magnetic core, the E 16/8/5 core geometry from Epcos TDK has been selected as it provides several different ferrite materials for practical comparison.

The T46 material has first been selected as it is the only ferrite material in E 16/8/5 core geometry whose relative permeability decreases when temperature increases. The associated temperature coefficient in the $\left[20^{\circ} \mathrm{C}-60^{\circ} \mathrm{C}\right]$ temperature range is estimated at $\left(\alpha_{\mu_{e}}\right)_{\mathrm{T} 46}=-9.1 \cdot 10^{-3} \mathrm{~K}^{-1}$. According to the definition of the electrical resonance angular frequency in Eq. (14) and since $\left(\alpha_{\mu_{e}}\right)_{\mathrm{T} 46}+\alpha_{C^{\varepsilon}}<0$, using the T46 ferrite material for the inductor should lead to a shift of the electrical resonance to higher frequency. For comparison, the N27 material has also been selected as its relative permeability increases with temperature. The associated temperature coefficient is estimated at $\left(\alpha_{\mu_{e}}\right)_{\mathrm{N} 27}=12.1 \cdot 10^{-3} \mathrm{~K}^{-1}$. Using the N27 ferrite material should lead to a larger mistuning of the resonant shunt because of a shift of the electrical resonance to lower frequency when the system is heated.

In [25, the temperature coefficient used for the inductance is $0.05 \cdot 10^{-3} \mathrm{~K}^{-1}$. It is calculated by taking into account the evolution of the synthetic inductor components with temperature. As this value is nearly 


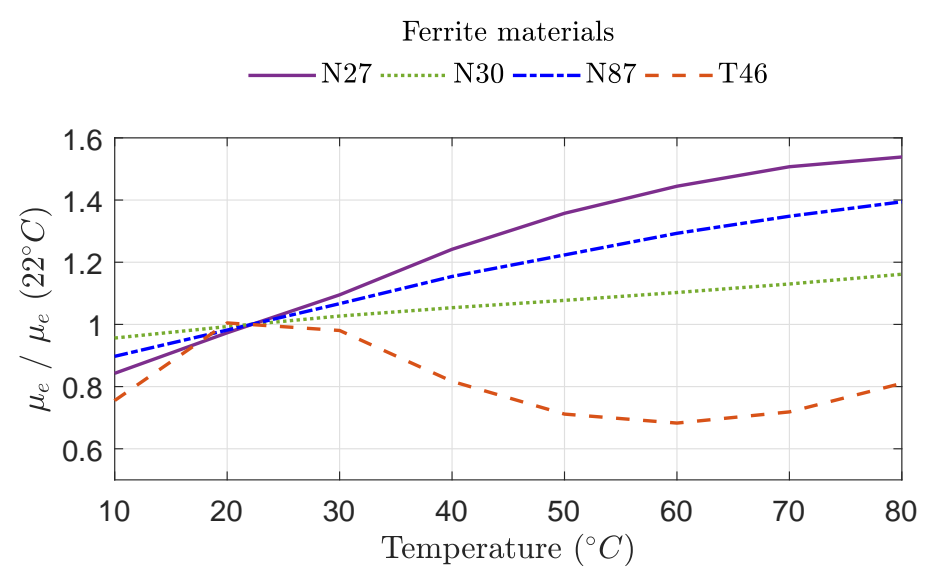

Figure 9: Relative permeability evolution with temperature of available ferrite materials in E 16/8/5 core geometry, extracted from datasheets.

\begin{tabular}{|c|c|c|c|c|c|c|c|c|}
\hline $\begin{array}{c}\text { Ferrite } \\
\text { material }\end{array}$ & $\begin{array}{c}\Omega_{\mathrm{e}} / 2 \pi \\
(\mathrm{Hz})\end{array}$ & $\begin{array}{c}C^{\varepsilon} \\
(\mathrm{nF})\end{array}$ & $\begin{array}{c}L \\
(\mathrm{H})\end{array}$ & $\begin{array}{c}A_{e} \\
\left(\mathrm{~mm}^{2}\right)\end{array}$ & $\begin{array}{c}l_{e} \\
(\mathrm{~mm})\end{array}$ & $\begin{array}{c}\mu_{0} \\
\left(\mathrm{H} \mathrm{m}^{-1}\right)\end{array}$ & $\mu_{e}$ & $N$ \\
\hline N27 & 322 & 38.3 & 6.38 & 20.1 & 37.6 & $4 \pi \times 10^{-7}$ & 1410 & 2600 \\
\cline { 1 - 5 } & & & & & & & &
\end{tabular}

Table 3: E 16/8/5 core geometry and ferrite materials specifications.

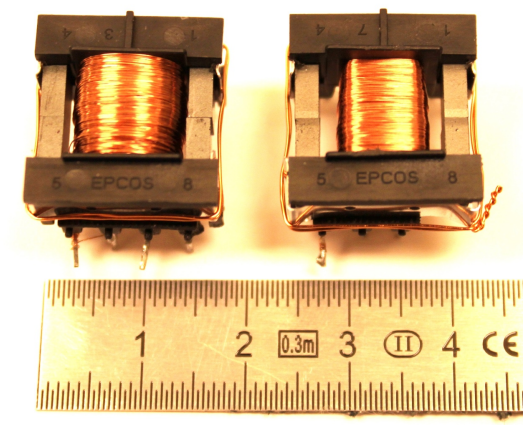

Figure 10: Produced inductive components. On the left: T46 ferrite material, 1120 turns, $0.1 \mathrm{~mm}$ wire diameter. On the right: N27 ferrite material, 2600 turns, $0.05 \mathrm{~mm}$ wire diameter.

a hundred times smaller than the ones used and measured in our work, the shunt detuning occurring in 25] is mainly owned to a variation of the piezoelectric capacitance.

Based on material and geometry characteristics, as well as values of $C^{\varepsilon}$ and $f_{\mathrm{e}}$, the number of wire turns is computed thanks to Eq. (14) and Eq. (21). All values are summed up in Table 3 The inductive components are shown in Fig. 10

\subsection{Air gap influence}

It is experimentally noticed that the measured inductance value $L_{\exp }$ at $322 \mathrm{~Hz}$ is below the target value of $6.38 \mathrm{H}$ (see Table 4). A reason for this difference is the discontinuity of the magnetic core, and more precisely the small air gap remaining between the two core parts which has a prime importance on the 


\begin{tabular}{|c|c|c|c|}
\hline $\begin{array}{c}\text { Ferrite } \\
\text { material }\end{array}$ & $N$ & $\begin{array}{c}L_{\exp } \\
(\mathrm{H})\end{array}$ & $\begin{array}{c}\delta \\
(\mu \mathrm{m})\end{array}$ \\
\hline $\mathrm{N} 27$ & 2600 & 6.14 & 1.1 \\
\hline $\mathrm{T} 46$ & 1120 & 5.69 & 0.6 \\
\hline
\end{tabular}

Table 4: Air gap of magnetic components.

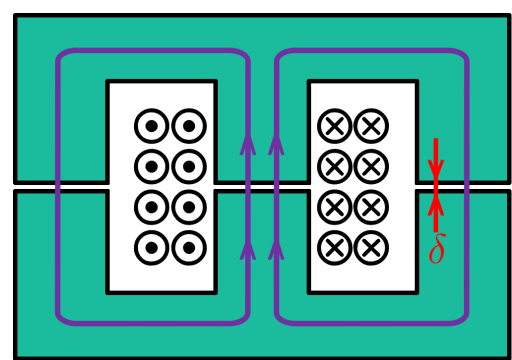

Figure 11: Side view of the E 16/8/5 core geometry with an air gap of length $\delta$, with magnetic field lines and windings represented.

inductance value. Taking the air gap into account, the electromagnetic circuit is represented in Fig. 11. As a consequence, the measured inductance value $L_{\exp }$ is

$$
L_{\exp }=\frac{N^{2}}{\Re_{1}+\Re_{2}},
$$

where $\Re_{1}$ and $\Re_{2}$ are the magnetic reluctances of the magnetic core, defined by

$$
\Re_{1}=\frac{l_{e}-\delta}{\mu_{e} \mu_{0} A_{e}}, \quad \Re_{2}=\frac{\delta}{\mu_{0} A_{e}},
$$

where $\delta$ is the air gap length. If $\delta=0$, the inductance value is the same as in Eq. (21). Knowing $N$, a measurement of $L_{\exp }$ at $322 \mathrm{~Hz}$ and the coil characteristics, one can estimate the air gap from Eq. 222 (see Table 4. An equivalent permeability $\mu_{\text {eq }}$ can then be defined writing

$$
\mu_{\mathrm{eq}}=\frac{l_{e} \mu_{e}}{l_{e}+\delta\left(\mu_{e}-1\right)} .
$$

Equation (24) shows that variations of $\mu_{e}$ caused by environmental parameters are attenuated as the air gap increases. Once the air gap is estimated, its value can be used to update datasheets, such as those represented in Fig. 9 .

\subsection{Temperature and electrical current characteristics}

The components are then characterized in temperature and electrical current with a LCR-meter at $322 \mathrm{~Hz}$. Dependence to the electrical current is also of primary importance because the inductance generated by conductive wires wound around a ferromagnetic core is generally dependent to the circulating electrical current. This effect was reported by V.E. Legg [37. In the case of piezoelectric shunt damping, Eq. (11) shows the electrical current is generated by vibrations of the mechanical structure, knowing the electrical current is $i=\dot{q}=\mathrm{j} \Omega q$ for sinusoidal excitation at angular frequency $\Omega$. The combined effects of temperature and sinusoidal electrical current of amplitude $i$ at $322 \mathrm{~Hz}$ are illustrated in Fig. 12 and Fig. 13. Testing values of electrical current are chosen to assure the LCR-meter works in its operating range. 


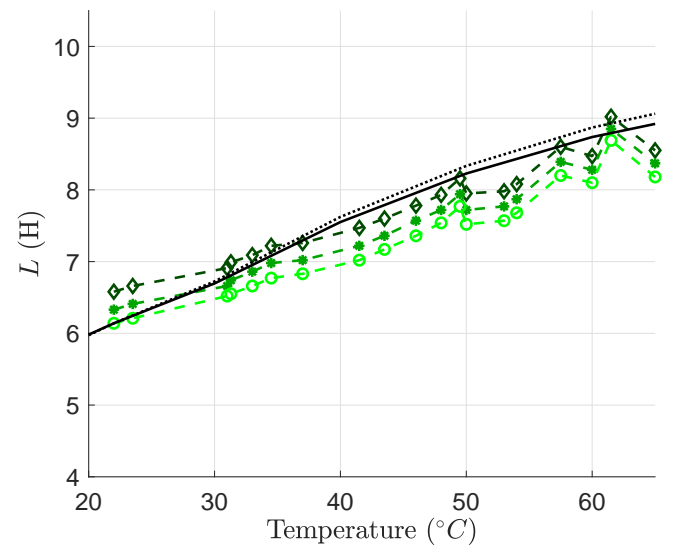

(a)

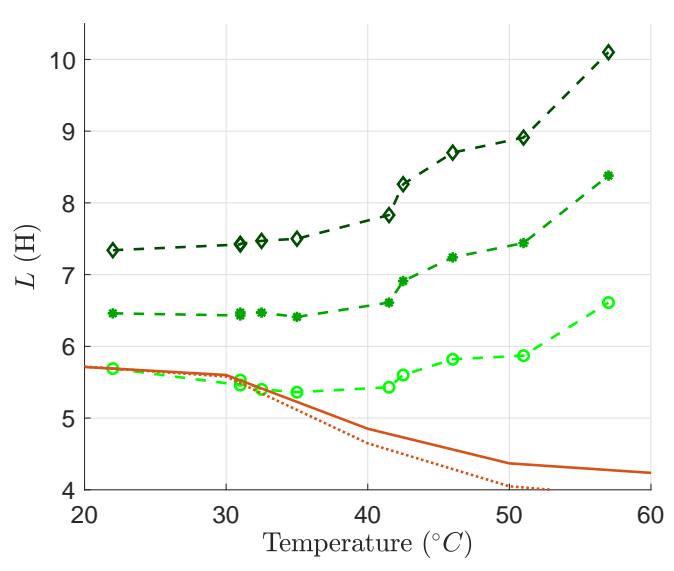

(b)

Figure 12: Influence of temperature for various electrical currents (a) on the N27 ferrite-based inductor and (b) on the T46 ferrite-based inductor.

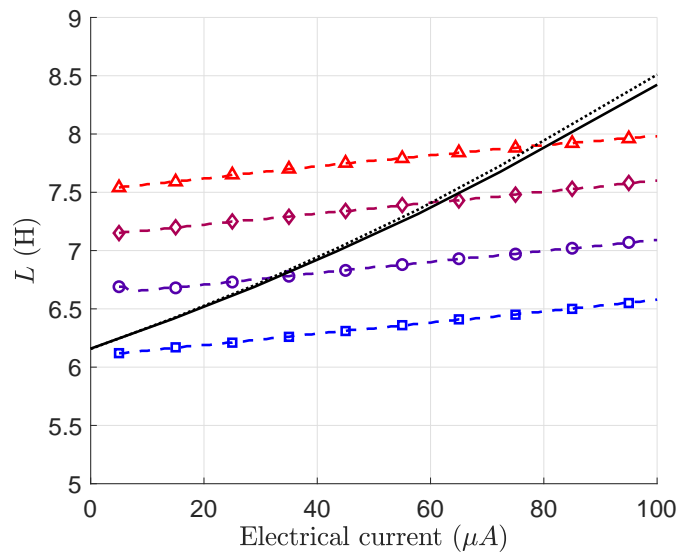

(a)
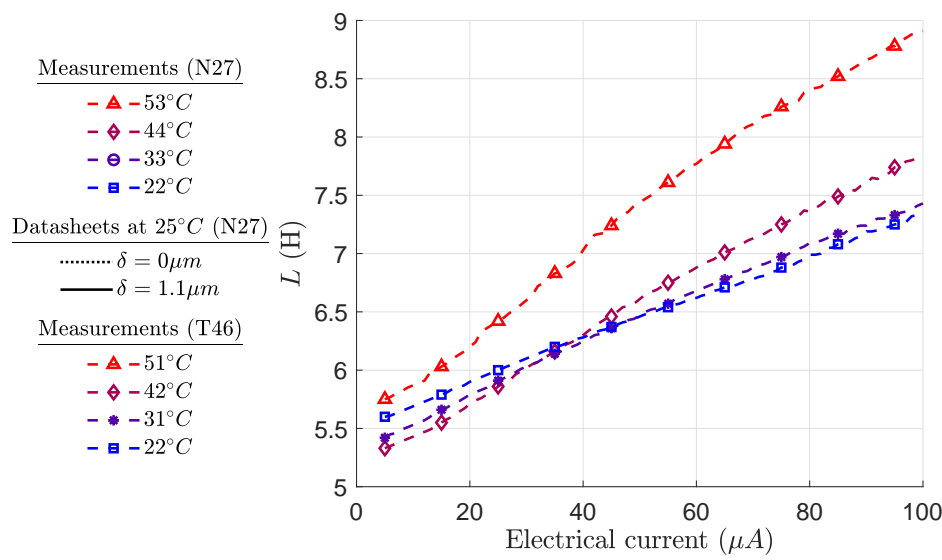

(b)

Figure 13: Influence of electrical current for various temperatures (a) on the N27 ferrite-based inductor and (b) on the T46 ferrite-based inductor.

Concerning the N27 ferrite-based inductor:

- In Fig. 12, it is shown that the N27 ferrite-based inductance evolves with temperature in agreement with data from core manufacturers. The updated datasheet that takes the estimated air gap into account predicts the inductance evolution quite well, even though it is noticeable that the air gap has little influence on it.

- In Fig. 13 it is shown that the N27 ferrite-based inductance does not increase with electrical current as much as datasheets imply, even when taking the remaining air gap in the component into account. A reason for such a difference is the testing frequency being $322 \mathrm{~Hz}$, as magnetic components are usually characterized at several $\mathrm{kHz}$. We noticed at room temperature an increase of the inductancecurrent characteristic slope with testing frequency. Compared to the test made at $322 \mathrm{~Hz}$ in Fig. 13 , 
the slope at $5 \mathrm{kHz}$ is around two times larger and therefore much closer to the available datasheet. Besides, it is noticed that the inductance characteristics seem independent from each other, since plotted data are just shifted from one another when temperature evolves. There is no obvious coupling between temperature and electrical current influences on the component, which makes its evolution with temperature easier to predict with datasheets.

Concerning the T46 ferrite-based inductor:

- In Fig. 12, it is shown that the T46 ferrite-based inductance decreases only for temperatures from $22^{\circ} \mathrm{C}$ to $40^{\circ} \mathrm{C}$ at low current levels. This evolution is roughly anticipated by the available datasheet, but the local temperature coefficient in these conditions is estimated at $\alpha_{L}=-4.5 \cdot 10^{-3} \mathrm{~K}^{-1}$, which is closer to $\alpha_{C^{\varepsilon}}$ than the value anticipated in subsection 3.3 . That means the resonant shunt should not get as much mistuned in this case as with the N27 ferrite-based inductance when temperature evolves. However, the mistuning should be worse for larger excitations, as the inductance does not even decrease from $22^{\circ} \mathrm{C}$ to $40^{\circ} \mathrm{C}$, before significantly increasing above $40^{\circ} \mathrm{C}$. A coupling between temperature and electrical current influences is thus noticed.

- In Fig. 13, it is shown that below $42^{\circ} \mathrm{C}$, inductance-current characteristics cross around $40 \mu \mathrm{A}$. Under $40 \mu \mathrm{A}$ and $42^{\circ} \mathrm{C}$, the inductance decreases when temperature rises, which represents the identified zone with a negative $\alpha_{L}$ in Fig. 12. For a current above $40 \mu \mathrm{A}$, the inductance rises with the temperature. This graph confirms there is a strong mutual dependence of temperature and electrical current effects on the T46 ferrite-based inductance. Unfortunately, no datasheet from core manufacturers is available for comparison.

The mutual dependence of temperature and electrical current influences on the inductance value is significant for the T46 ferrite-based inductor, and negligible for the N27 ferrite-based inductor. A deeper study would be required to explain and forecast this coupling effect, as available datasheets are not sufficient. This practical characterization shows nonetheless that we can benefit from the T46 ferrite-based inductance decrease at low temperatures and low excitation levels to counterbalance part of the piezoelectric capacitance increase with temperature.

\section{Vibration damping of a clamped beam}

Two ferrite materials have been chosen to make inductive components dedicated to vibration mitigation of the second bending mode of a cantilever beam. The objective is now to compare the evolution with temperature of vibration damping offered by resonant shunts made with these two components. The experiments are conducted at low excitation levels to take advantage of the T46 ferrite-based inductance decrease spotted in Fig. 12. The damping performance of the resonant shunt is tested using the experimental setup described in Fig. 5 and Fig. 6. The resistance value is deliberately tuned at room temperature to be smaller than theoretical values of reference tuning methods [6, 15, 18, as it allows better perception of shunt tuning evolutions.

The model developed in section 2 is represented by Eq. (13). A mechanical damping $\xi_{\mathrm{m}}$ is added to this model, as it better fits with the transfer function of the experimental system in open-circuit. The optimal electrical parameters defined in Eq. (15) are supposed correct, as $\xi_{\mathrm{m}}$ is small compared to the electrical damping $\xi_{\mathrm{e}}$ 6]. Furthermore, the data acquisition setup considers the electrical current in the solenoid as the excitation, rather than the dimensionless force applied at the free end of the beam. Since these two quantities are supposed proportional, a constant gain $G^{\star}$ is added to the model as well. Hence the model becomes:

$$
\frac{U}{F / K^{D}}=\frac{G^{\star}\left[1+2 \mathrm{j} \frac{\xi_{\mathrm{e}}}{\Omega_{\mathrm{e}}} \Omega-\left(\frac{\Omega}{\Omega_{\mathrm{e}}}\right)^{2}\right]}{\left[1+2 \mathrm{j} \frac{\xi_{\mathrm{m}}}{\Omega_{\mathrm{O}}} \Omega-\left(\frac{\Omega}{\Omega_{\mathrm{O}}}\right)^{2}\right]\left[1+2 \mathrm{j} \frac{\xi_{\mathrm{e}}}{\Omega_{\mathrm{e}}} \Omega-\left(\frac{\Omega}{\Omega_{\mathrm{e}}}\right)^{2}\right]-\frac{k_{\mathrm{c}}^{2}}{1+k_{\mathrm{c}}^{2}}} .
$$




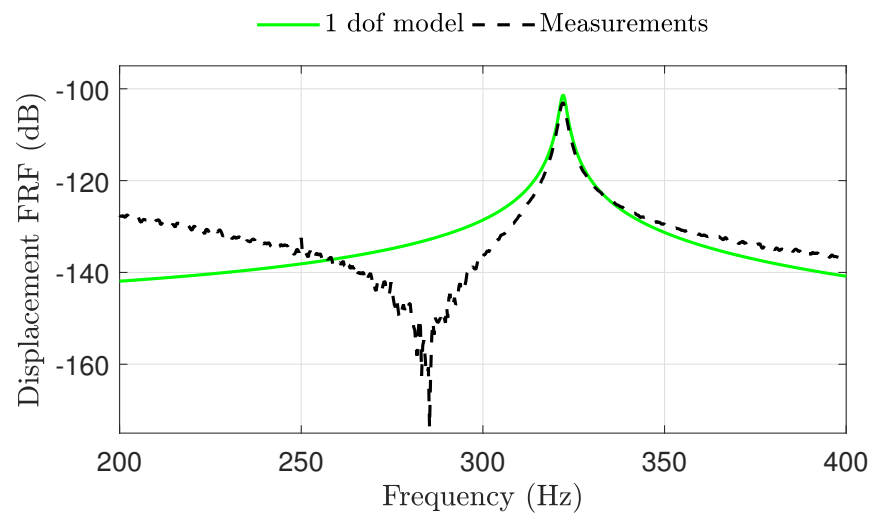

Figure 14: Open-circuit experimental and model FRFs at room temperature.

\begin{tabular}{|c|c|c|c|c|c|c|}
\hline $\begin{array}{c}\text { Ferrite } \\
\text { material }\end{array}$ & $k_{\mathrm{c}}$ & $\begin{array}{c}\Omega_{\mathrm{O}} / 2 \pi \\
(\mathrm{Hz})\end{array}$ & $\xi_{\mathrm{m}}$ & $\begin{array}{c}\Omega_{\mathrm{e}} / 2 \pi \\
(\mathrm{Hz})\end{array}$ & $\xi_{\mathrm{e}}$ & $\begin{array}{c}G^{\star} \\
(\mathrm{dB})\end{array}$ \\
\hline N27 & \multirow{2}{*}{0.12} & 322.1 & $2.9 \cdot 10^{-3}$ & 325.4 & $5.0 \cdot 10^{-2}$ & -146.1 \\
\cline { 4 - 7 } $\mathrm{T} 46$ & & $2.7 \cdot 10^{-3}$ & 324.1 & $3.4 \cdot 10^{-2}$ & -144.0 \\
\hline
\end{tabular}

Table 5: Parameters used in the model of Eq. 25 for piezoelectric shunts using N27 and T46 ferrite-based inductors.

Six model parameters have to be identified. The coupling factor $k_{\mathrm{c}}$ has been measured using Eq. (8). Since the one degree-of-freedom mechanical model cannot predict the antiresonance near $285 \mathrm{~Hz}$, the fitting interval is set as [ $315 \mathrm{~Hz}-350 \mathrm{~Hz}]$. The mechanical resonance angular frequency $\Omega_{\mathrm{O}}$ and structural damping $\xi_{\mathrm{m}}$ are defined by fitting the open-circuit measured and model FRFs by a least squares method. The result of this fitting is shown in Fig. 14. Then, the electrical resonance angular frequency $\Omega_{\mathrm{e}}$, the electrical damping $\xi_{\mathrm{e}}$ and the gain $G^{\star}$ are defined by fitting the shunted system FRF at room temperature with the model in Eq. 25) by a least squares method. All identified quantities are given in Table 5 .

Finally, temperature behavior models extracted from preliminary tests (see Fig. 7. Fig. 8 and Fig. 12) are used to compute the theoretical transfer function at different temperatures. The comparison between measured and computed transfer functions is made in Fig. 15 and Fig. 16.

Concerning the resonant shunt damping with a N27 ferrite-based inductor (see Fig. 15):

- In experimental results, it is shown the temperature has a significant effect on the damping performance. The resonant shunt gets mistuned as soon as temperature rises, as the peak initially at $340 \mathrm{~Hz}$ shifts to lower frequency and increases of around $11 \mathrm{~dB}$ from $22^{\circ} \mathrm{C}$ to $61{ }^{\circ} \mathrm{C}$. This is in good agreement with a decrease of the electrical resonance frequency with temperature, induced by the increase of both the piezoelectric capacitance and the inductance seen in Fig. 8 and Fig. 12

- The developed model predicts the shift to lower frequency of the initial peak at $340 \mathrm{~Hz}$. Its amplitude is however not well estimated, as it increases of around $18 \mathrm{~dB}$. This difference can be attributed to two main causes. On one hand, the evolution with temperature of the other model parameters, such as the electrical damping $\xi_{\mathrm{e}}$ and the coupling factor $k_{\mathrm{c}}$, are not taken into account. While not having a strong influence on the tuning of the resonant shunt, they have an effect on the overall damping performance [6]. On the other hand, the one degree-of-freedom mechanical model cannot predict the experimental antiresonance near $285 \mathrm{~Hz}$ initially, which influences the results [19]. 


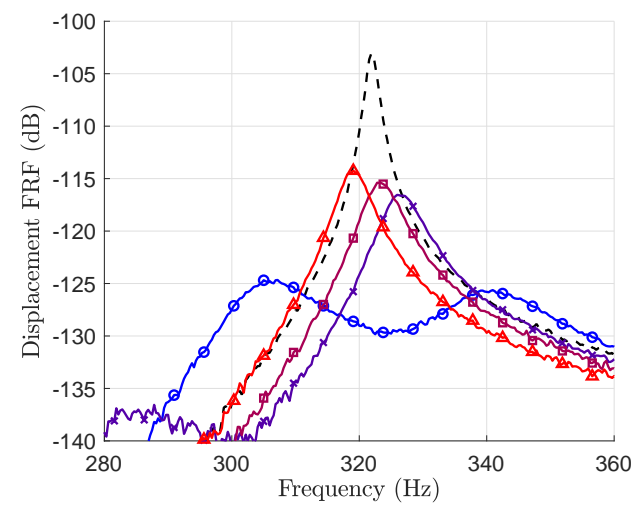

(a)
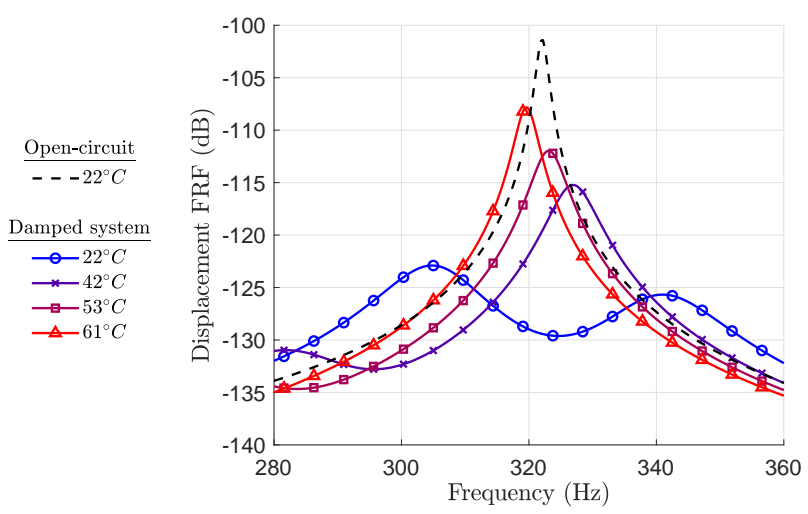

(b)

Figure 15: (a) Experimental and (b) model transfer functions at different temperatures with a N27 ferrite-based inductor in the resonant shunt.

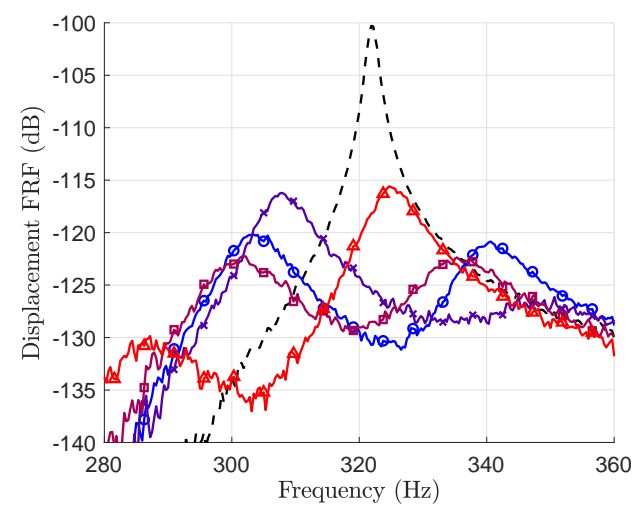

(a)
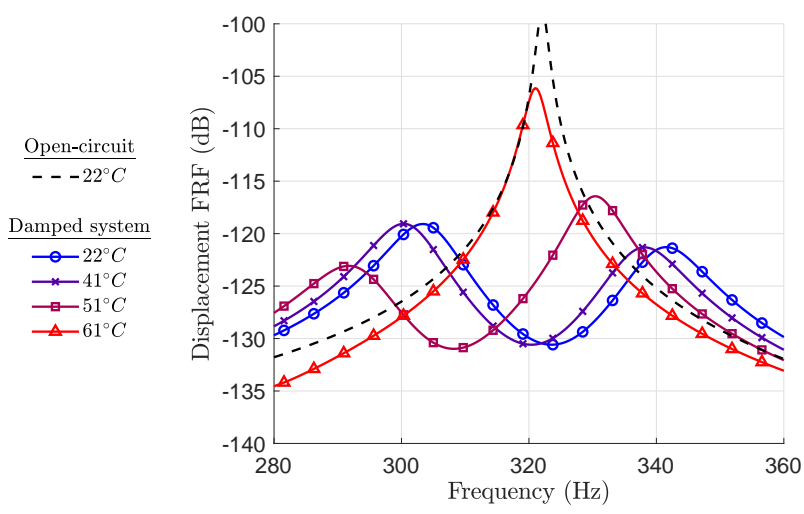

(b)

Figure 16: (a) Experimental and (b) model transfer functions at different temperatures with a T46 ferrite-based inductor in the resonant shunt.

Concerning the resonant shunt damping with a T46 ferrite-based inductor (see Fig. 16):

- The temperature has a significant effect on the damping performance in this case as well. However, the shunt mistuning only occurs above $51^{\circ} \mathrm{C}$, which means the decrease of inductance with temperature for low levels of excitation seen in Fig. 12 can be used to counterbalance the increase of piezoelectric capacitance. In the end, the shift of the initial peak at $340 \mathrm{~Hz}$ leads to an attenuation deterioration of around $5 \mathrm{~dB}$ at $61^{\circ} \mathrm{C}$, as the inductance increases greatly above $40^{\circ} \mathrm{C}$.

- The developed model predicts the shift to lower frequency of the initial peak at $340 \mathrm{~Hz}$ as soon as temperature rises. At $61^{\circ} \mathrm{C}$, the peak has increased of around $15 \mathrm{~dB}$, which is far from the measured increase of $5 \mathrm{~dB}$. It seems the experimental shunt tuning benefits from a clear decrease of the inductance value, as it has initially been predicted in Fig. 9, while the inductance seems not to increase as much as when tested alone above $42^{\circ} \mathrm{C}$ (see Fig. 12). The strong mutual dependence of temperature and electrical current effects on the inductance make difficult the prediction of the shunt performance based on Fig. 12 and Fig. 13 alone, as the experimental excitation is a white-noise signal. Finally, the observed 
differences between experimental and modelling results could also be explained by the same reasons invoked for the differences seen in Fig. 15: variations with temperature of other model parameters, as well as the approximation resulting from of the one degree-of-freedom mechanical model.

In both cases, knowing the temperature characteristics of inductive components from datasheets and direct measurements does not lead to efficient prediction of performance. A further study could use a frequency-sweep excitation at fixed amplitude to limit the effect of the current-temperature mutual dependence. However, it has been shown that using a T46 ferrite-based inductor helps mitigating the shunt detuning when temperature changes. A notable mistuning occurs only above around $50{ }^{\circ} \mathrm{C}$, while mistuning occurs as soon as temperature rises in the case of a shunt made with a N27 ferrite-based inductor. For this reason, there is a real interest in adequately choosing the ferrite material of the inductive component to make a fully passive adaptive resonant shunt.

\section{Conclusions}

In this paper, the objective is to design a passive self-tuning resonant shunt considering temperature variations. A tuning criterion is derived from an electromechanical model of the vibrating structure connected to a resonant shunt. Since the mechanical resonance frequency and the piezoelectric capacitance variations with temperature are considered as input data, the design parameter is the evolution of the circuit inductance with temperature. The inductors are designed so that the variable permeabilities of the magnetic cores counterbalance the mechanical resonance frequency and the piezoelectric capacitance variations. A practical investigation on the second bending mode of a cantilever beam is performed. After evaluating the temperature coefficients of the mechanical resonance angular frequency and the circuit capacitance, a magnetic core geometry and two ferrite materials are selected for the inductor. For the sake of comparison, these two ferrite materials are chosen with opposite temperature variations of their relative permeabilities. In the end, experiments are conducted to prove the interest of designing an inductor with an adequate ferrite material. The concept is validated since the resonant shunt tuning is maintained from $22{ }^{\circ} \mathrm{C}$ to around $50{ }^{\circ} \mathrm{C}$ with one of the produced inductor, while this is not the case with the other one. Hence the ferrite material should be selected according to the circuit capacitance and the mechanical resonance frequency variations. While the defined temperature range was from room temperature to $60{ }^{\circ} \mathrm{C}$ for practical reasons, the approach would have been the same at lower or higher temperatures with different ferrite materials.

The design of a fully passive and adaptive resonant shunt on a larger temperature range would require predictive models of electrical components temperature behavior. However, it has been remarked that our design conditions do not always match with testing conditions of data from manufacturers. Furthermore, characterizations of the obtained components show that a strong mutual dependence of temperature and electrical current characteristics may happen. This could prevent the passive adaptive tuning of the resonant shunt from happening if the mechanical excitation varies too much, and it also makes the shunt performance harder to predict. A solution would be to consider both temperature and excitation amplitude as environmental parameters that may cause a mistuning of the resonant shunt. The design of the inductor would then have to involve both temperature and magnetization characteristics of the considered ferromagnetic materials.

\section{References}

[1] R. L. Forward, Electronic damping of vibrations in optical structures, Applied Optics 18 (1979) $690-697$.

$[2]$ N. W. Hagood, A. Von Flotow, Damping of structural vibrations with piezoelectric materials and passive electrical networks, Journal of Sound and Vibration 146 (1991) 243-268.

[3] J. P. Den Hartog, Vibrations, McGraw-Hill Book Company, 1956.

[4] S. Wu, Piezoelectric shunts with a parallel R-L circuit for structural damping and vibration control, in: Proceedings SPIE, volume 2720, 1996, pp. 259-269. URL: https://doi.org/10.1117/12.239093 doi 10.1117/12.239093

[5] G. Caruso, A critical analysis of electric shunt circuits employed in piezoelectric passive vibration damping, Smart Materials and Structures 10 (2001) 1059-1068.

[6] O. Thomas, J. Ducarne, J.-F. Deü, Performance of piezoelectric shunts for vibration reduction, Smart Materials and Structures 21 (2012) 015008. 
[7] K. Yamada, Complete passive vibration suppression using multi-layered piezoelectric element, inductor, and resistor, Journal of Sound and Vibration 387 (2017) 16-35.

[8] J. J. Hollkamp, Multimodal passive vibration suppression with piezoelectric materials and resonant shunts, Journal of Intelligent Material Systems and Structures 5 (1994) 49-57.

[9] S. Wu, Method for multiple mode piezoelectric shunting with single PZT transducer for vibration control, Journal of Intelligent Material Systems and Structures 9 (1998) 991-998.

[10] S. Behrens, S. O. R. Moheimani, A. J. Fleming, Multiple mode current flowing passive piezoelectric shunt controller, Journal of Sound and Vibration 266 (2003) 929-942.

[11] M. Berardengo, S. Manzoni, A. M. Conti, Multi-mode passive piezoelectric shunt damping by means of matrix inequalities, Journal of Sound and Vibration 405 (2017) 287-305.

[12] S. Vidoli, F. dell'Isola, Modal coupling in one-dimensional electromechanical structured continua, Acta Mechanica 141 (2000) 37-50.

[13] P. Bisegna, G. Caruso, F. Maceri, Optimized electric networks for vibration damping of piezoactuated beams, Journal of Sound and Vibration 289 (2006) 908-937.

[14] B. Lossouarn, J.-F. Deü, M. Aucejo, Multimodal vibration damping of a beam with a periodic array of piezoelectric patches connected to a passive electrical network, Smart Materials and Structures 24 (2015) 115037.

[15] K. Yamada, H. Matsuhisa, H. Utsuno, K. Sawada, Optimum tuning of series and parallel LR circuits for passive vibration suppression using piezoelectric elements, Journal of Sound and Vibration 329 (2010) 5036-5057.

[16] P. Soltani, G. Kerschen, G. Tondreau, A. Deraemaeker, Piezoelectric vibration damping using resonant shunt circuits: an exact solution, Smart Materials and Structures 23 (2014) 125014.

[17] M. Berardengo, A. Cigada, S. Manzoni, M. Vanali, Vibration control by means of piezoelectric actuators shunted with LR impedances: Performance and robustness analysis, Shock and Vibration 2015 (2015) 1-30.

[18] P. Gardonio, D. Casagrande, Shunted piezoelectric patch vibration absorber on two-dimensional thin structures: Tuning considerations, Journal of Sound and Vibration 395 (2017) 26-47.

[19] J. Høgsberg, S. Krenk, Calibration of piezoelectric RL shunts with explicit residual mode correction, Journal of Sound and Vibration 386 (2017) 65-81.

[20] U. Andreaus, M. Porfiri, Effect of electrical uncertainties on resonant piezoelectric shunting, Journal of Intelligent Material Systems and Structures 18 (2007) 477-485.

[21] J. Ducarne, Modeling and optimisation of non-linear vibration damping by switch shunting of piezoelectric elements, Theses, Conservatoire national des arts et metiers - CNAM, 2009. URL: https://tel.archives-ouvertes.fr/tel-00464513

[22] M. W. Hooker, Properties of PZT-based piezoelectric ceramics between $-150^{\circ} \mathrm{C}$ and $250^{\circ} \mathrm{C}$, Technical Report, NASA, 1998.

[23] C. Miclea, C. Tanasoiu, L. Amarande, C. F. Miclea, C. Plavitu, M. Cioangher, L. Trupina, C. T. Miclea, C. David, Effect of temperature on the main piezoelectric parameters of a soft PZT ceramic, Romanian Journal of Information Science and Technology 10 (2007) 243-250.

[24] A. Belloli, D. Niederberger, S. Pietrzko, M. Morari, P. Ermanni, Structural vibration control via R-L shunted active fiber composites, Journal of Intelligent Material Systems and Structures 18 (2006) 275-287.

[25] J.-W. Park, J.-H. Han, Sensitivity analysis of damping performances for passive shunted piezoelectrics, Aerospace Science and Technology 33 (2014) 16-25.

[26] D. Niederberger, M. Morari, An autonomous shunt circuit for vibration damping, Smart Materials and Structures 15 (2006) 359-364

[27] J. J. Hollkamp, T. F. Starchville, A self-tuning piezoelectric vibration absorber, Journal of Intelligent Material Systems and Structures 5 (1994) 559-566.

[28] D. Niederberger, A. J. Fleming, S. O. R. Moheimani, M. Morari, Adaptive multi-mode resonant piezoelectric shunt damping, Smart Materials and Structures 13 (2004) 1025-1035.

[29] B. Lossouarn, J.-F. Deü, G. Kerschen, A fully passive nonlinear piezoelectric vibration absorber, Philosophical Transactions of the Royal Society of London A: Mathematical, Physical and Engineering Sciences (In Press) (2018).

[30] IEEE standard on piezoelectricity, 1988. doi 10.1109/ieeestd.1988.79638

[31] F. A. Firestone, A new analogy between mechanical and electrical systems, The Journal of the Acoustical Society of America 4 (1933) 249-267.

[32] A. Bloch, Electromechanical analogies and their use for the analysis of mechanical and electromechanical systems, Journal of the Institution of Electrical Engineers - Part I: General 92 (1945) 157-169.

[33] PI Ceramic, Piezoelectric ceramic products: Fundamentals, characteristics and applications, 2016.

[34] B. de Marneffe, A. Preumont, Vibration damping with negative capacitance shunts: theory and experiment, Smart Materials and Structures 17 (2008) 035015.

[35] A. Preumont, Vibration Control of Active Structures, 3rd ed., Springer Netherlands, 2011. URL: http://www.ebook.de/ de/product/19293363/a_preumont_vibration_control_of_active_structures.html

[36] B. Lossouarn, M. Aucejo, J.-F. Deü, B. Multon, Design of inductors with high inductance values for resonant piezoelectric damping, Sensors and Actuators A: Physical 259 (2017) 68-76.

[37] V. E. Legg, Magnetic measurements at low flux densities using the alternating current bridge, Bell System Technical Journal 15 (1936) 39-62. 